\title{
CUACE/Dust - an integrated system of observation and modeling systems for operational dust forecasting in Asia
}

\author{
S. L. Gong ${ }^{1,2}$ and X. Y. Zhang ${ }^{2}$ \\ ${ }^{1}$ Centre for Atmosphere Watch and Services of CMA, Chinese Academy of Meteorological Sciences, Beijing 100081, China \\ ${ }^{2}$ Air Quality Research Division, Science and Technology Branch, Environment Canada, 4905 Dufferin Street, Toronto, \\ Ontario, M3H 5T4, Canada
}

Received: 21 May 2007 - Published in Atmos. Chem. Phys. Discuss.: 18 July 2007

Revised: 25 March 2008 - Accepted: 23 April 2008 - Published: 5 May 2008

\begin{abstract}
An integrated sand and dust storm (SDS) forecasting system - CUACE/Dust (Chinese Unified Atmospheric Chemistry Environment for Dust) has been developed, which consists of a comprehensive dust aerosol module with emission, dry/wet depositions and other atmospheric dynamic processes, and a data assimilation system (DAS) using observational data from the CMA (China Meteorological Administration) ground dust monitoring network and retrieved dust information from a Chinese geostationary satellite - FY$2 \mathrm{C}$. This is the first time that a combination of surface network observations and satellite retrievals of the dust aerosol has been successfully used in the real time operational forecasts in East Asia through a DAS. During its application for the operational SDS forecasts in East Asia for spring 2006, this system captured the major 31 SDS episodes observed by both surface and satellite observations. Analysis shows that the seasonal mean threat score (TS) for $0-24 \mathrm{~h}$ forecast over the East Asia in spring 2006 increased from 0.22 to 0.31 by using the DAS, a $41 \%$ enhancement. The time series of the forecasted dust concentrations for a number of representative stations for the whole spring 2006 were also evaluated against the surface $\mathrm{PM}_{10}$ monitoring data, showing a very good agreement in terms of the SDS timing and magnitudes near source regions where dust aerosols dominate. This is a summary paper for a special issue of ACP featuring the development and results of the forecasting system.
\end{abstract}

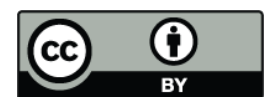

Correspondence to: S. L. Gong (sunling.gong@ec.gc.ca)

\section{Introduction}

Sand and dust storms (SDS) have caused devastating damages to properties and human health every spring in East Asia. Under the major influence of global climate changes and meteorology over the Asian dust source regions and minor from anthropogenic desertification (Zhang et al., 2003b), the source strength of Asian SDS was estimated to be $\sim 800 \mathrm{Mt} /$ year (Zhang et al., 1997) with very high spatial and temporal variability from year to year (Gong et al., 2006a). Recently there has been an increasing concern over the formation and transport of soil dust aerosol and its contribution to the earth-climate system, essentially to the impact of a severe form of soil dust aerosol in the atmosphere - SDS. Because of its economical and social impacts, it is critical to understand the source strength, transport and deposition of soil dust and to establish the SDS forecasting and early warning (EW) capacity in the world to reduce its impact. Within this context, an ambitious plan to establish a global SDS forecasting and early warning system is now being organized by WMO (World Meteorological Organization) to improve the global forecasting ability for SDS around the world.

There are a number of SDS forecasting systems now operational at various organizations including the Dust Regional Atmospheric Model - DREAM (Nickovic et al., 2001) providing 72-h forecasts for the Mediterranean region, the Navy Aerosol Analysis and Prediction System - NAAPS (Christensen, 1997) providing the global SDS forecasts, Chemical weather Forecasting model System - CFORS (Uno et al., 2003) and the Asian Dust Aerosol Model - ADAM (Park and In, 2003) providing the SDS forecasts for Asia. Researches have shown that the existing dust forecasting models possess a certain degree of skills to forecast a general picture of a dust

Published by Copernicus Publications on behalf of the European Geosciences Union. 


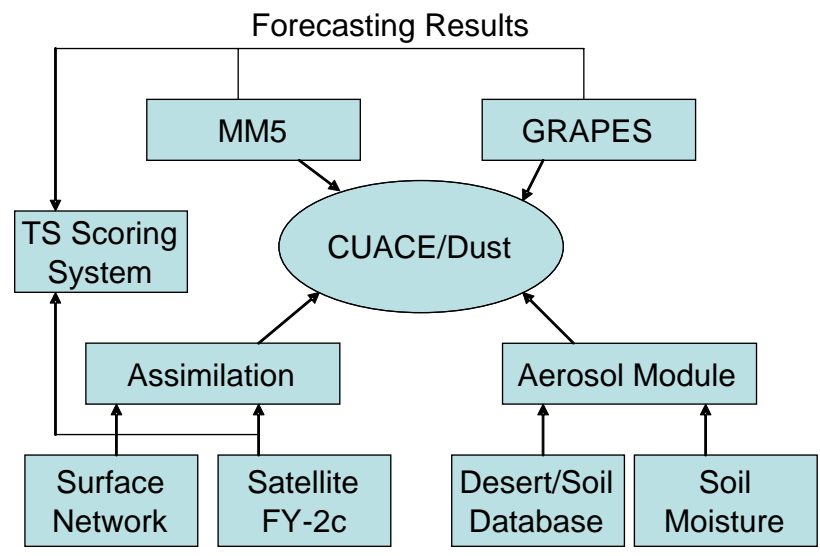

Fig. 1. The structure of CUACE/Dust under two weather forecasting models: MM5 and GRAPES.

episode in Asia (Uno et al., 2006) but differ substantially in forecasting details. One of the reasons for the difference was the difficulty in the identification of source regions accurately and the lack of near-real time observational data for the SDS to validate the dust emission parameterizations in those models. Various methods have been used to enhance the accuracy of the dust model forecasts. For example, using the TOMS satellite data as an initial field, Alpert et al. (2002) found that TOMS-based initialization has a significant positive impact on all the scores for the dust storm forecasts.

In the mean time, a number of new developments have been achieved recently in China to formulate an integrated SDS forecasting system based on previous researches. The CUACE/Dust (Chinese Unified Atmospheric Chemistry Environment for Dust) modeling system in China has been transferred from a research model into an operational forecasting system of SDS since 2004. This system consists of a comprehensive dust aerosol module with emission, dry/wet depositions and other atmospheric dynamic processes, and a data assimilation module using observational data from the CMA (China Meteorological Administration) ground dust monitoring network and retrieved dust information from a Chinese geostationary satellite - FY-2C. By evaluating the performance of the forecasting system against observations, substantial insights into the predictability of the dust storms have been obtained that will benefit the future improvement of the system.

This special issue of scientific papers is dedicated to the development of the CUACE/Dust system and its applications to the spring 2006 SDS operational forecasts. This paper summarizes the major highlights of papers in the issue.

\section{CUACE/Dust structure}

CUACE is a newly developed system for air quality/climate researches and forecasts in China that includes four func- tional modules for treating aerosols, gas phase chemistry, emissions and data assimilation. Since it is envisioned as a unified system, it can be implemented into any meteorological models such as regional air quality and climate models. CUACE/Dust is an application of CUACE to dust aerosol forecasts and is an integrated system that combines a sizesegregated multi-component aerosol module (Gong et al., 2003a) with a 3D-Var data assimilation system implemented into two operational weather forecasting models (Fig. 1). The dust module (Gong et al., 2003b, 2006b) has been used for Asian dust aerosol studies during ACE-Asia and reasonable agreements have been achieved between various surface measurements (Zhang et al., 2003a) and air-borne observations. During the spring 2006, CUACE/Dust was implemented on-line into two meteorological frameworks: MM5 (Zhou et al., 2008) and GRAPES (Global/Regional Assimilation and PrEdiction System) which is the newest generation of Chinese weather forecast model (Xue, 2004). Running at $108 \mathrm{~km}$ and $50 \mathrm{~km}$ horizontal resolutions, respectively, MM5 and GRAPES with CUACE/Dust delivers $24 \mathrm{~h}, 48 \mathrm{~h}$ and $72 \mathrm{~h}$ forecasts of dust storms twice a day for the Asian area. Full details of the CUACE/Dust developments and evaluations for MM5 are given by Zhou et al. (2008) in this special issue. The results with GRAPES will be published elsewhere.

Data assimilation is a key component in the CUACE/Dust system, which needs near real-time measurements of dust aerosols (concentrations and visibility) at ground stations, vertical profiles from lidar and spatial coverage from satellites. In a paper by Hu et al. (2008), the detailed methodology to retrieve the dust intensity from the Chinese geostationary FY-2C satellite is given with validations from the ground network observation data. Niu et al. (2007) developed the dust assimilation module in CUACE/Dust by combining the satellite and surface network data to form a coherent data set with a method proposed to treat the dust data under clouds where a satellite is unable to detect SDS.

Finally, a threat scoring (TS) system was established in a GIS framework to evaluate the forecasting results with all the observational data sets (Wang et al., 2008). This system uses the same principles for evaluating the routine precipitation forecasts to compute the threat score (TS), miss ratio (MR), false alarm ratio (FAR), and bias score (BS) and accuracy (AC) for the whole model domain or part of the domain.

\section{Major results and findings}

\subsection{Synoptic features of 2006 SDS}

Spring 2006 was featured as one of the most favourable seasons for dust productions in Asia (Yang et al., 2008) with 31 SDS episodes reported in East Asia. Synoptic analysis indicated that during the transitional period from winter to spring of 2005-2006, there was a fast developing high center across the upper troposphere and circumpolar vortices, which 


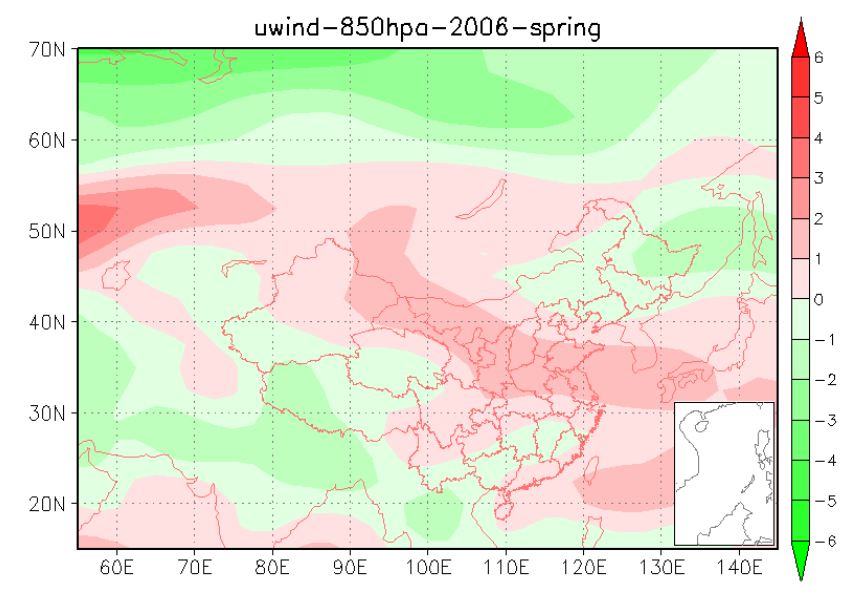

Fig. 2. Zonal wind anomalies at $850 \mathrm{hPa}$ for spring 2006 showing the systematic positive anomalies over most of the source regions in Asia.

pushed the prevailing area of circumpolar vortices further to mid-latitudes. Furthermore, an apparent abnormal westerly jet was developed at the mid-level of troposphere and right side of the circumpolar vortices, across the mid-high latitude areas of Asia (Yang et al., 2008). Both of these conditions favoured the production and transport of SDS. Figure 2 shows clearly the zonal wind anomalies at $850 \mathrm{hPa}$ for spring 2006. It is evident that most of the source regions in China and Mongolia were under positive wind anomalies which are much larger than those for 2003, a year with the least SDS in the last 7 years. Detailed analysis of these features is given by Yang et al. (2008). A special feature in this paper is the introduction of a SDS process or episode definition, which groups a number of incidents of SDS in a period and region according to the synoptic circulation pattern associated with them. This analysis combines the surface observations of SDS with a systematic circulation that causes the occurrences of observed SDS and provides a systematic way to analyze the SDS and its impacts. Using the process numbers of SDS in China and the surface $\mathrm{PM}_{10}$ observations at the North America by IMPROVE network from 2000 to 2005 (Malm et al., 1994), a very good correlation was obtained (Fig. 3). It implies that the process number of Chinese SDS has a significant control on the variability in background PM over much of the western North America. A detailed analysis of more stations from IMPROVE and possible reasons for the correlations are given in a paper by Zhao et al. (2007) of this special issue.

\subsection{Observation data as inputs for CUACE/Dust}

During the spring 2006, a number of dust monitoring networks were also operating to measure the $\mathrm{PM}_{10}$ concentrations and visibilities in the source and receptor regions in China (Wang et al., 2008). Figure 4 illustrates the distribu-

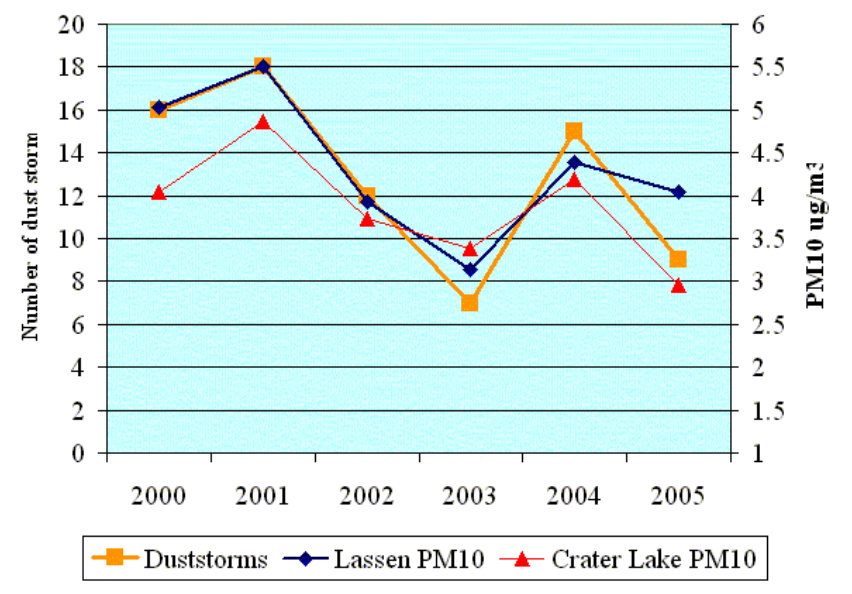

Fig. 3. Relationship between the annual spring (March-May) mean $\mathrm{PM}_{10}$ concentration at 2 sites in the western US and SDS process numbers in China from 2000 to 2005. The 2 sites are Lassen, CA; Crater Lake, OR.

tion of surface observation stations that provide on-line $\mathrm{PM}_{10}$ and 3-h visual visibility measurements during the dust storm periods. Wang et al. (2008) demonstrated that there were three SDS occurrence centers, western China source, Mongolian source and northern China source from SDS observation in East Asia in springs of 2001-2006. PM 10 characteristics and its relationship with visibility were derived using the observational data in northern China from spring 2004 to 2006 , showing a power function relationship in each station especially during SDS events with the $R^{2}$ of about 0.8 in source areas (Fig. 4). The establishment of the relationship between $\mathrm{PM}_{10}$ and visibility enables the conversion of large number of visibility monitoring data into $\mathrm{PM}_{10}$ values during the dust periods that can be used for both dust model evaluations and input data required by the SDS data assimilation system.

At the same time, the Chinese geostationary satellite FY$2 \mathrm{C}$ was operational to provide the retrieved dust distribution in Northeast Asia, including North China, Mongolia, Korea and Japan, covering $70^{\circ} \mathrm{E}-140^{\circ} \mathrm{E}$ and $25^{\circ} \mathrm{N}-60^{\circ} \mathrm{N}$. The retrieved SDS distributions and the surface $\mathrm{PM}_{10}$ observations were compared in Fig. 5 with a very reasonable agreement of dust distribution. The retrieval schemes and validation processes were discussed in details by $\mathrm{Hu}$ et al. (2008). A SDS distribution was generated from all the observational results at one hour interval every day. Methodology and evaluation of the data merging from various observational platforms are discussed in the data assimilation (Niu et al., 2007).

\subsection{Data assimilation system (DAS)}

The SDS data assimilation system (DAS) for CUACE/Dust played an important role in achieving the good performance of SDS forecasts in spring 2006. The system is based on a 




Fig. 4. SDS observation stations by the CMA. The red dots are meteorological stations with visual visibility measurements and the blue squares are SDS observation stations with $\mathrm{PM}_{10}$ and instrumental visibility measurements. Insert: Relationship between hourly-averaged $\mathrm{PM}_{10}$ concentration and visibility during SDS events in the springtime at Tazhong station.

three dimensional variational method (3D-Var) and uses extensively the measurements of $\mathrm{PM}_{10}$, surface visibility and dust loading retrieval from the Chinese geostationary satellite FY-2C as described in Sect. 3.2. This is the first time that a combination of surface network observations and satellite retrievals of the dust aerosol has been successfully used in the real time operational forecasts in East Asia through a DAS. During the data retrievals of dust aerosol from the geostationary FY-2C satellite, a robust algorithm for identifying the dust clouds was developed and a relationship between the retrieved dust intensity - SDS-IDDI (Infrared Difference Dust Index) and surface visibility observations was established at various regions in East Asia (Hu et al., 2008; Niu et al., 2007). This enables the date merging of satellite data with surface observations to form a complete coverage of SDS for the DAS. Figure 6 displays the differences for the forecasts of the 10 April SDS with and without DAS system. More results are given in a paper by Niu et al. (2007) in this special issue.

Forecasting results shows that the seasonal mean TS for 0-24 h forecast over the East Asia in spring 2006 increased from 0.22 to 0.31 by using the DAS, a $41 \%$ enhancement (Niu et al., 2007). For some SDS processes, the TS can reach as high as 0.55 (Zhou et al., 2008).

\subsection{6 spring forecasting results}

To further evaluate the performance of the CUACE/Dust system, a detailed comparison of the modeling predictions for the 8-12 March episode with surface network observations and lidar measurements was carried out and revealed a robust forecasting ability of the system (Zhou et al., 2008). A comparison of model forecasted SDS and the surface observed $\mathrm{PM}_{10}$ is given in Fig. 7 for three forecasting times at a station close to the source region of SDS in Northeast China with a very reasonable agreement. The time series of the forecasted dust concentrations for a number of representative stations for the whole spring 2006 were also evaluated against the surface $\mathrm{PM}_{10}$ monitoring data, showing a very good agreement in terms of the SDS timing and magnitudes near source regions where dust aerosols dominate (Zhou et al., 2008). The threat score in the whole spring of 2006 was $0.31,0.23$ and 0.21 for the $24 \mathrm{~h}, 48 \mathrm{~h}$ and $72 \mathrm{~h}$ forecasts, respectively, while the accuracy for the same three time forecasts reached as high as 0.88 compared with the observations.

\section{Challenges in future SDS forecasts}

An accurate SDS forecasting system replies on a number of well-developed sub-systems which includes a robust meteorological model, a well-performed model for dust aerosols 

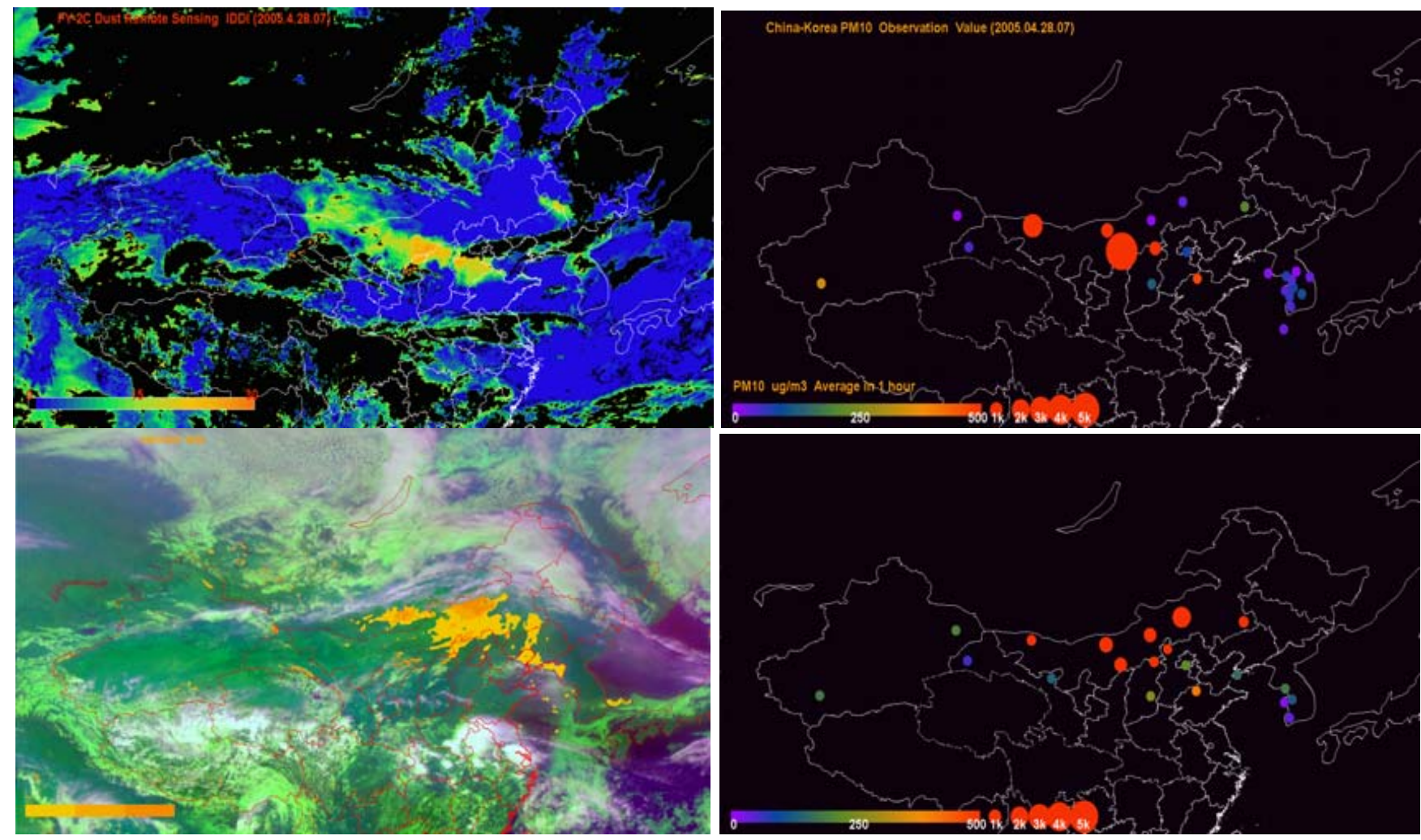

Fig. 5. FY-2C IDDI comparison with $\mathrm{PM}_{10}$ values on 28-29 April 2005. The plots at the left hand side show the satellite retrieved SDS distributions and the right hand side plots show the PM measurements at the same time.
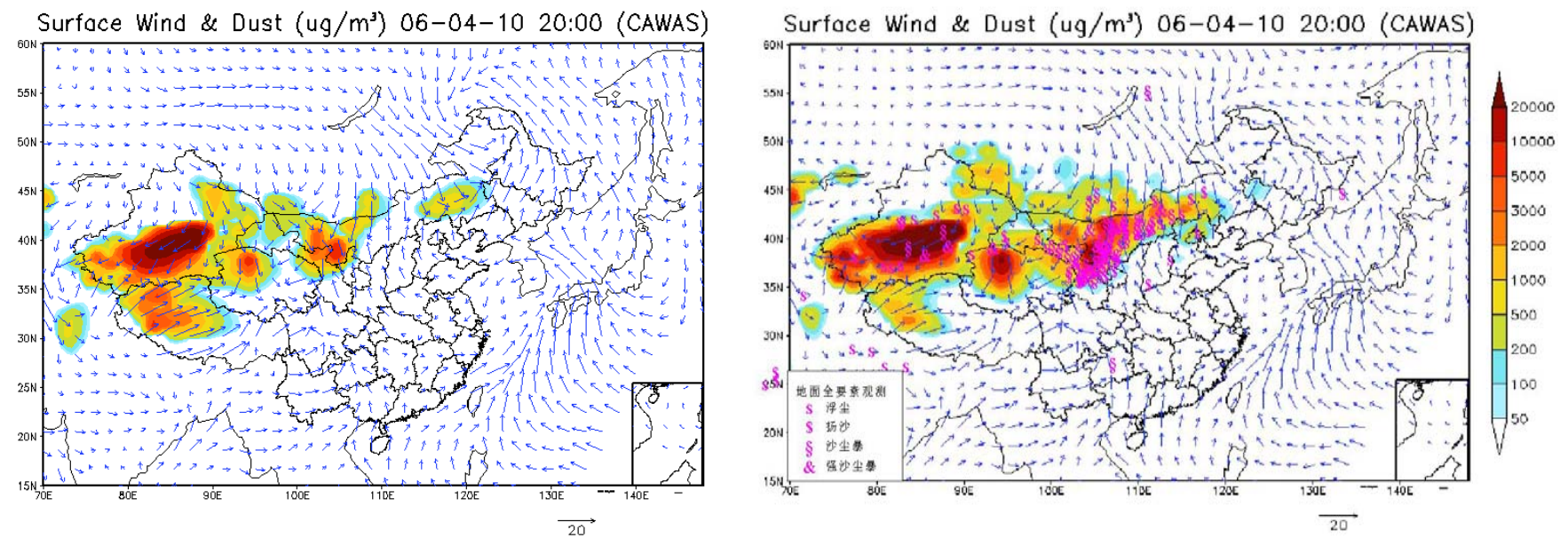

Fig. 6. Comparisons of CUACE/Dust forecasting results for 10 April 2006 with and without data assimilation. The symbols of "S", "\$", "§", "\&" indicate floating dust, blowing dust, SDS, severe SDS, respectively, obtained from surface meteorological stations by CAWAS (Centre for Atmosphere Watch and Services, CMA).

microphysics and dynamics in the atmosphere and a system of timely surface, air-borne and space observational networks for atmospheric dust aerosols.

Meteorological models provide critical components to compute the production, transports and removals of dust aerosols. Forecasted meteorological parameters such as the surface wind speeds, precipitations, turbulent mixing in the boundary, convective mixing to the troposphere and westerly jets all contribute to the accuracy of SDS forecasts for its spatial and temporal distributions. Developments of 
Zhurihe

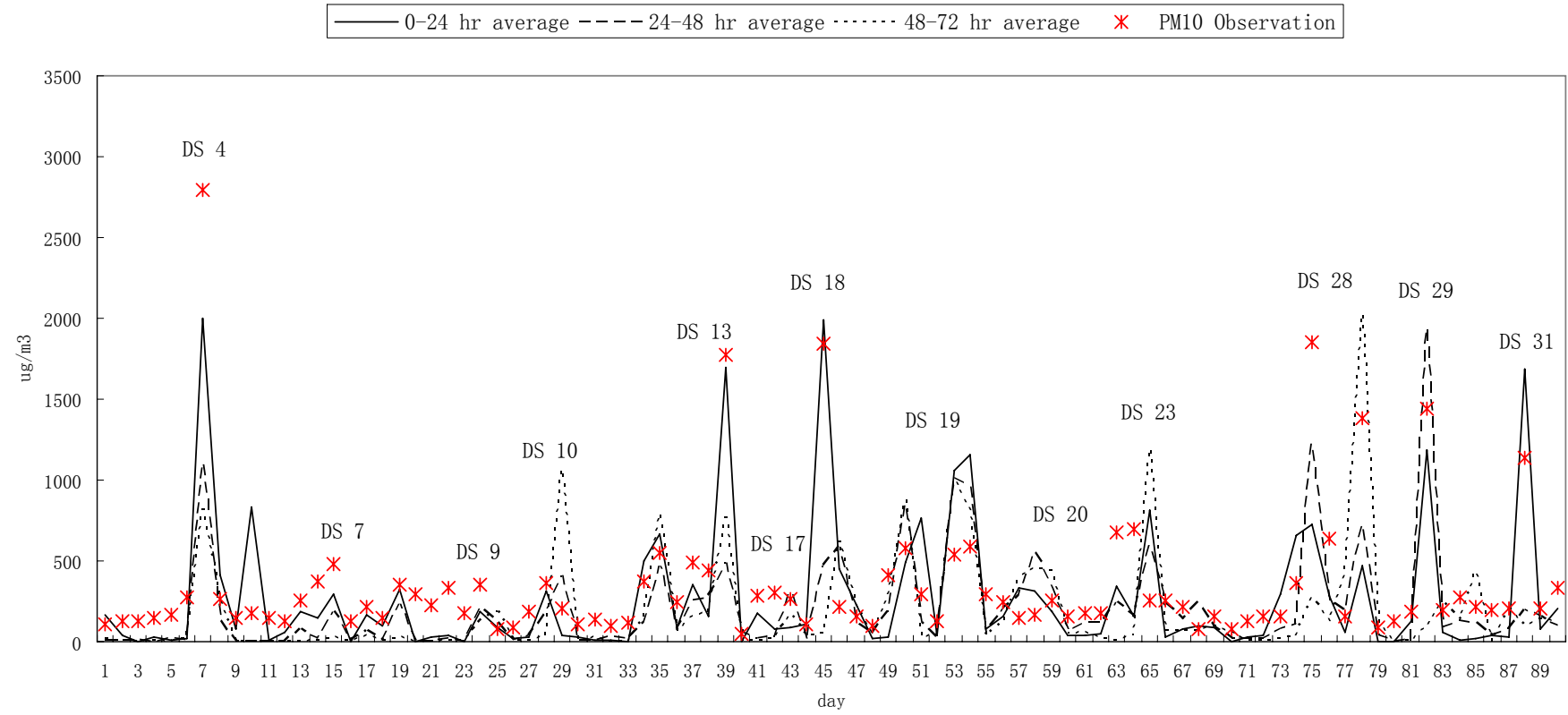

Fig. 7. Comparisons of the surface 24-h mean SDS concentration by 0-24h (FT1), 24-48 h (FT2) and 48-72 h (FT3) forecasts and the surface $\mathrm{PM}_{10}$ observation for the entire spring from 3 March to 31 May for Zhurihe $\left(42.40^{\circ} \mathrm{N}, 112.90^{\circ} \mathrm{E}\right)$, a station in the west of Onqin Daga sandy areas.

well-behaved meteorological models are critical in achieving a successful SDS forecasting system. The THORPEX (THe Observing system Research and Predictability EXperiment) program under the $\mathrm{WMO}$ is responding to the weather related challenges of the 21 st century to accelerate improvements in the accuracy of 1-day to 2-week high impact weather forecasts, which will greatly benefit the SDS forecasts.

Having a good metrological model is just the beginning of the SDS forecasting system. A dust aerosol model that uses the forecasted metrological parameters to simulate the dust emission and deposition entails realistic emission and deposition schemes as well as necessary geographic data bases for them. Firstly, an accurate updating of global or regional desert distributions or source regions still remains a challenge for some critical regions, especially for those regions that have changed due to desertification or reverse process. Satellites provide a global picture of desert distributions but miss a number of source regions (Gong et al., 2003b) in China. High resolution data of global desert distributions and soil texture properties are urgently needed. This is also important to characterize the radiative forcing of dust aerosols (Sokolik et al., 2001).

These data are fed in a dust emission scheme that computes the dust emission flux as a function of surface properties and meteorological conditions such as $10-\mathrm{m}$ wind speeds, snow cover and soil moisture. Currently, there are a number of dust emission schemes ranging from a simple function of wind speed or friction velocity to detailed physically based formulations as summarized in DMIP Dust Model Intercomparison Project (Uno et al., 2006). However, most of the physically-based schemes require global distributions of some key parameters (Zhao et al., 2006). In situ observations of the wind erosion process revealed that the vertical profile of moving sand has a clear size dependency with height and saltation flux and that threshold wind velocity is dependent on soil moisture. Researches also demonstrated that saltation flux is strongly dependent on the parent soil size distribution of the desert surface (Uno et al., 2006). Measurements of dust flux, accurate/updated land-use information and soil surface properties as a function of surface wind speed at various regions of the globe are needed to calibrate model parameters.

A robust dust aerosol model needs to accurately simulate the dust dry and depositions as a function of particle size, which determines the life time and concentrations of dust aerosols in the atmosphere. Very limited observations of dry and wet fluxes available to evaluate the model performance pose a challenge to fine-tune the parameters used in both dry and wet deposition schemes (Slinn and Slinn, 1981a, b; Zhang et al., 1993).

In the development of CUACE/Dust for an accurate SDS forecasts, the requirement for a comprehensive monitoring network of dust aerosols has surfaced as the paramount component to constitute a good SDS forecasting system. First of all, the monitoring data of SDS provide the observed reality to check the model performance and improve the model 
parameters (Wang et al., 2008; Zhou et al., 2008). In addition to this, in the course of SDS forecasts, near real-time network observation data facilitate the data assimilation system to be used in the operational forecasts. However, current observation data lack both spatial and temporal coverage. Horizontally, the density of the network stations is not enough to yield a complete picture, e.g. in China (Wang et al., 2008), of SDS. Further more, in the current SDS networks, no direct measurements of dust aerosols are taken at real time. The $\mathrm{PM}_{10}$ and visibility provide a close surrogate to the dust aerosols, but work reasonably well only at source regions where dust particles dominate. Satellite observations provide the horizontal coverage but only for a column loading and with some problems in retrieving SDS over the bright land surfaces. The lack of vertical structure of SDS is being resolved by surface lidar networks around the globe such as the European lidar network (EARLINET) and the Asian Dust Network (AD-Net), which start to provide near real-time vertical structure of SDS. The ultimate challenge for the observational community is to formulate a system to integrate different types of measurements of SDS from synoptic visibility, $\mathrm{PM}_{10}$, satellite dust intensity, optical depth and lidar vertical structures into a coherent data set in a timely manner for the SDS DAS. CUACE/Dust has incorporated the concept of integration in the data treatment (Hu et al., 2008; Niu et al., 2007) for the DAS, but more researches and regional collaborations are needed to form a regional or even global system of SDS observations for both model validation and real time forecasting applications.

Acknowledgements. The authors wish to thank for the financial supports from the MOST (2004DIB3J115) and the National Basic Research Program (973) (2006CB403703 and 2006CB403701) of China for this project.

Edited by: Y. Balkanski

\section{References}

Alpert, P., Krichak, S. O., Tsidulko, M., Shafir, H., and Joseph, J. H.: A Dust Prediction System with TOMS Initialization, Mon. Weather Rev., 130, 2335-2345, 2002.

Christensen, J. H.: The Danish Eulerian Hemispheric ModelAa three-dimensional air pollution model used for the Arctic, Atmos. Environ., 31, 4169-4191, 1997.

Gong, S. L., Barrie, L. A., Blanchet, J.-P., Salzen, K. V., Lohmann, U., Lesins, G., Spacek, L., Zhang, L. M., Girard, E., Lin, H., Leaitch, R., Leighton, H., Chylek, P., and Huang, P.: Canadian Aerosol Module: A size-segregated simulation of atmospheric aerosol processes for climate and air quality models 1. Module development, J. Geophys. Res., 108, 4007, doi:10.1029/2001JD002002, 2003a.

Gong, S. L., Zhang, X. Y., Zhao, T. L., McKendry, I. G., Jaffe, D. A., and Lu, N. M.: Characterization Of Soil Dust Distributions In China And Its Transport During ACE-ASIA 2. Model Simulation and Validation, J. Geophys. Res., 108, 4262, doi:10.1029/2002JD002633, 2003b.
Gong, S. L., Zhang, X. Y., Zhao, T. L., Zhang, X. B., Barrie, L. A., McKendry, I. G., and Zhao, C. S.: A simulated climatology of Asian dust aerosol and its trans-Pacific transport. Part II: Interannual variability and climate connections, J. Climate, 19, 104-122, 2006a.

Gong, S. L., Zhang, X. Y., Zhao, T. L., Zhang, X. B., Barrie, L. A., McKendry, I. G., and Zhao, C. S.: A simulated climatology of Asian dust aerosol and its trans-Pacific transport. Part II: Interannual variability and climate connections, J. Climate, 19, 104-122, 2006b.

Hu, X. Q., Lu, N. M., Niu, T., and Zhang, P.: Operational retrieval of Asian sand and dust storm from FY-2C geostationary meteorological satellite and its application to real time forecast in Asia, Atmos. Chem. Phys., 8, 1649-1659, 2008, http://www.atmos-chem-phys.net/8/1649/2008/.

Malm, W. C., Sisler, J. F., Huffman, D., Eldred, R. A., and Cahill, T. A.: Spatial and seasonal trends in particle concentration and optical extinction in the United States, J. Geophys. Res., 99, 13471370, 1994.

Nickovic, S., Kallos, G., Papadopoulos, A., and Kalaliagou, O.: A model for prediction of desert dust cycle in the atmosphere, J. Geophys. Res., 106, 18 113-18 129, 2001.

Niu, T., Gong, S. L., Zhu, G. F., Liu, H. L., Hu, X. Q., Zhou, C. H., and Wang, Y. Q.: Data assimilation of dust aerosol observations for CUACE/Dust forecasting system, Atmos. Chem. Phys. Discuss., 7, 8309-8332, 2007, http://www.atmos-chem-phys-discuss.net/7/8309/2007/.

Park, S. U. and In, H.-J.: Parameterization of dust emission for the simulation of the Yellow Sand (Asian dust) event observed in March 2002 in Korea, J. Geophys. Res., 108(D19), 4618, doi:10.1029/2003JD003484, 2003.

Slinn, S. A. and Slinn, W. G. N.: Modeling of atmospheric particulate deposition to natural water, in: Atmospheric Pollutants in Natural Waters, edited by: Eisenreich, S. J., Ann Arbor Science, Michigan, pp. 23-53, 1981a.

Slinn, S. A. and Slinn, W. G. N. (Eds.): Modeling of atmospheric particulate deposition to natural waters, Atmospheric Pollutants in Natural Waters, Ann Arbor Sci., Ann Arbor, Michigan, pp. 23-53, $1981 b$.

Sokolik, I. N., Winker, D. M., Bergametti, G., Gillette, D. A., Carmichael, G., Kaufman, Y., Gomes, L., Schuetz, L., and Penner, J. E.: Introduction to special section: Outstanding problems in quantifying the radiative impacts of mineral dust, J. Geophys. Res., 106, 18 015-18 028, 2001.

Uno, I., Carmichael, G. R., Streets, D. G., Tang, Y., Yienger, J. J., Satake, S., Wang, Z., Woo, J.-H., Guttikunda, S., Uematsu, M., Matsumoto, K., Tanimoto, H., Yoshioka, K., and Iida, T.: Regional Chemical Weather Forecasting System CFORS: Model Descriptions and Analysis of Surface Observations at Japanese Island Stations During the ACE-Asia Experiment, J. Geophys. Res., 108(D23), 8668, doi:10.1029/2002JD002845, 2003.

Uno, I., Wang, Z., Chiba, M., Chun, Y. S., Gong, S. L., Hara, Y., Jung, E., Lee, S.-S., Liu, M., Mikami, M., Music, S., Nickovic, S., Satake, S., Shao, Y., Song, Z., Sugimoto, N., Tanaka, T., and Westphal, D. L.: Dust model intercomparison (DMIP) study over Asia: Overview, J. Geophys. Res., 111, D12213, doi:10.1029/2005JD006575, 2006.

Wang, Y. Q., Zhang, X. Y., Gong, S. L., Zhou, C. H., Hu, X. Q., Liu, H. L., Niu, T., and Yang, Y. Q.: Surface observation of sand 
and dust storm in East Asia and its application in CUACE/Dust, Atmos. Chem. Phys., 8, 545-553, 2008, http://www.atmos-chem-phys.net/8/545/2008/.

Xue, J.: Progresses of Researches on Numerical Weather Prediction in China: 1999-2002, Adv. Atmos. Sci., 21(3) 467-474, 2004.

Yang, Y. Q., Hou, Q., Zhou, C. H., Liu, H. L., Wang, Y. Q., and Niu, T.: Sand/dust storm processes in Northeast Asia and associated large-scale circulations, Atmos. Chem. Phys., 8, 25-33, 2008, http://www.atmos-chem-phys.net/8/25/2008/.

Zhang, X., Arimoto, R., An, Z., Chen, T., Zhu, G., and Wang, $X .:$ Atmospheric trace elements over source regions for Chinese dust: Concentrations, sources and atmospheric deposition on the Loess Plateau, Atmos. Environ., 27, 2051-2067, 1993.

Zhang, X. Y., Arimoto, R., and An, Z. S.: Dust emission from Chinese desert sources linked to variations in atmospheric circulation, J. Geophys. Res., 102, 28 041-28 047, 1997.

Zhang, X. Y., Gong, S. L., Shen, Z. X., Mei, F. M., Xi, X. X., Liu, L. C., Zhou, Z. J., Wang, D., Wang, Y. Q., and Cheng, Y.: Characterization of soil dust aerosol in China and its transport/distribution during 2001 ACE-Asia. 1. Network Observations, J. Geophys. Res., 108(D9), 4261, doi:10.1029/2002JD002632, 2003a.
Zhang, X. Y., Gong, S. L., Zhao, T. L., Arimoto, R., Wang, Y. Q., and Zhou, Z. J.: Sources of Asian dust and role of climate change versus desertification in Asian dust emission, Geophys. Res. Lett., 30, 2272, doi:10.1029/2003GL018206, 2003b.

Zhao, T. L., Gong, S. L., Zhang, X. Y., Abdel-Mawgoud, A., and Shao, Y. P.: An assessment of dust emission schemes in modeling east Asian dust storms, J. Geophys. Res., 111, D05S90, doi:10.1029/2004JD005746, 2006.

Zhao, T. L., Gong, S. L., Zhang, X. Y., and Jaffe, D. A.: Asian dust storm influence on North American ambient PM levels: observational evidence and controlling factors, Atmos. Chem. Phys. Discuss., 7, 9663-9686, 2007, http://www.atmos-chem-phys-discuss.net/7/9663/2007/.

Zhou, C. H., Gong, S. L., Zhang, X. Y., Wang, Y. Q., Niu, T., Liu, H. L., Zhao, T. L., Yang, Y. Q., and Hou, Q.: Development and evaluation of an operational SDS forecasting system for East Asia: CUACE/Dust, Atmos. Chem. Phys., 8, 787-798, 2008, http://www.atmos-chem-phys.net/8/787/2008/. 